\title{
تقويم المنهج الدراسي لمواد الاختيارية في قسم اللغة العربية وأدبها \\ بكلية الإنسانية بجامعة مولانا مالك إبراهيم الإسلامية الحكومية مالانج
}

\author{
Laili Fitriani \\ الجامعة الاسلامية الحكومية مولانا مالك إبراهيم مالانج \\ laily@bsa.uin-malang.ac.id
}

\begin{abstract}
Abstrak
Evaluasi kurikulum memegang peranan penting bagi pengambilan kebijakan dan keputusan dalam pembelajaran. Hasil-hasil evaluasi kurikulum akan bermanfaat bagi penentuan kebutuhan mahasiswa, begitu pula halnya dengan adanya matakuliah pilihan yang dipasarkan di Jurusan Bahasa dan Sastra Arab Fakultas Humaniora UIN Maulana Malik Ibrahim Malang.

Penelitian ini bertujuan untuk (1) Mengevaluasi kurikulum mata kuliah keterampilan/skill di Jurusan Bahasa dan Sastra Arab; dan (2) Mendeskripsikan konstribusi matakuliah keterampilan/skill secara teoritis dan praktis bagi mahasiswa jurusan Bahasa dan Sastra Arab angkatan 2014 dalam kegiatan Praktek Kerja Lapangan Integratif (PKLI).

Penelitian ini menggunakan metode deskriptif kualitatif dengan model penelitian evaluatif. Pengumpulan data dilakukan dengan teknik wawancara dan dokumentasi.

Hasil penelitian ini adalah: (1) Perlu adanya evaluasi kurikulum Jurusan Bahasa dan Sastra Arab secara terus menerus dengan memperhatikan analisis kebutuhan mahasiswa dalam kegiatan PKLI; (2) Mayoritas matakuliah memiliki konstribusi positif dan sangat bermanfaat dalam kegiatan PKLI.
\end{abstract}

Kata Kunci: Evaluasi kurikulum, matakuliah pilihan, Bahasa dan Sastra Arab.

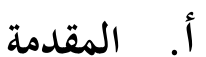

$$
\begin{aligned}
& \text { المنهج هو عامل من عوامل التعليم والتربية التي تحتاج إلى اهتمام في عملية }
\end{aligned}
$$

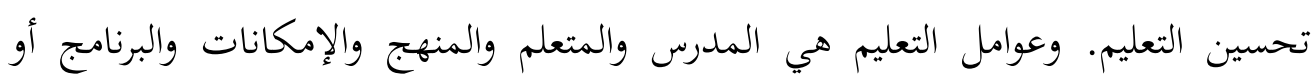

$$
\begin{aligned}
& \text { الهدف والمجتمع. (مهيمين: 2007: 119-120). المنهج عنصر أساسي من عناصر العلمية } \\
& \text { التعليمية، إن لم يكن صلبها، والسبب في ذلك أنه يقدم تصورا شاملا لما ينبغي أن يقدم } \\
& \text { للطالب من معلومات، وما يجب أن من مهارات، وما يمكن أن ينمى لديه من قيم } \\
& \text { واتجاهات. (طعيمة، 1989: 59). } \\
& \text { وعند صالح ذياب هندي تخضع المناهج الدراسية لعمليات نقد ومراجعة وتقييم } \\
& \text { مستمرة، وذلك بسبب مجموعة من العوامل التي تفرض التغيّر في حاجات المجتمع } \\
& \text { وحاجات المتعلمين، كما تفرضه في طبيعة المعرفة ونوعها، وفي طبيعة طرق التدريس } \\
& \text { والأنظمة التعليمية. وعليه فإن المناهج الدراسية التي توضع في فترة زمنية معينة قد تصبح }
\end{aligned}
$$


قليلة الأهمية ومحدودة الجدوى بعد عشر سنوات، إذا لم تتعرّض لعمليات المراجعة والنقد والإضافة والحذف والتبديل. (هندي، 1987: 155-156).

إن العوامل المؤثرة في المناهج الدرسية متعددة، ومن أهمها: المجتمع والطلبة وطبيعة المعرفية. فالمجتمع مثلا يتعرض لعمليات تغيير مستمرة، تشمل أساليبه وحاجاته ومشكلاته، كما تشمل قيمه وتطلعاته وطموحاته. لذلك كان من الصعب على المنهج الدرسي أن يبقى متكيفا مع حاجات المجتمع فترة زمنية طويلة، مما يعني ضرورة تغييره في ضوء التغييرات التي يمر بها المجتمع. ومن الثابت أن التغيرات التي تحدث في المجتمع تؤدي إلى إحداث تغيير في حاجات أفراده. ذلك أن الأفراد يتأثرون سيكولوجيا بالتغيرات الاجتماعية، ويواجهون مشكلات التغير الاجتماعي، فتبرز لديهم حاجات جديدة وتختفي حاجات قديمة، مما يجعلهم مضطرين إلى تغيير أساليب تكيفهم مع المشكلات الجديدة. وهذا يتطلب أن تكون المناهج المدروسة قادرة على تزويدهم بالمهارات المناسبة للتكيّف

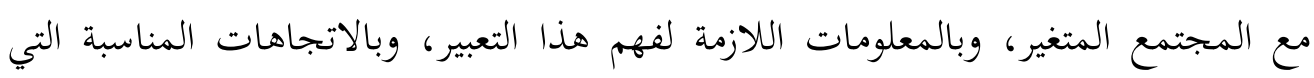
نمكنهم من التعامل بفاعلية مع التغيرات الاجتماعية. وفضلا عن ذلك فإن التفجر المعرفي الذي يعد من أبراز سمات هذا العصر، يؤثر بشكل مباشر على المناهج الدراسية. فالمعلومات تتزايد بأطراد، والحقائق تتغير بشكل مستمر، مما يستوجب ضرورة إحداث تغيير في المناهج المدررسية، حتى يتمكن الطالب من الاتصال الدائم بالحقائق والمعارف الجديدة.

التقويم هو تحديد قيمة الأشياء، وهو الحكم على مدى نجاح الأعمال والمشروعات وقد استخدم الإنسان التقويم بصوره المختلفة وأساليبه المتنوعة منذ كانت هنالك أمامه غايات ينبغي الوصول إليها، وآمال يسعى إلى تحقيقها، وأعمال يمارسها. وقد تزايدت أهمية التقويم بالنسبة لجميع الناس وفق التقدم الحضاري وتعقد أمر الحياة وتزايد أهمية الطاقة التي يبذلها الإنسان والمال الذي يُنفقه والوقت الذي يتطلبه أداء الأعمال.

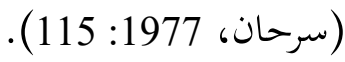

لقد أصبح التقويم ركنا أساسيا من أركان أي شروع أو نشاط يمارسه الإنسان في حياته. والتقويم هو معرفة مدى ما حققناه من نجاح. والنجاح هو بلوغ الأهداف. وعلى

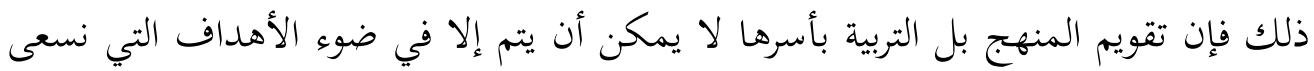
إلى تحقيقها. ولذلك فإن الخطوة الأولى في أي تقويم تتمثل في تحديد الأهداف المنشودة. ثم يأتي بعد ذلك اختيار الوسائل والأدوات التي تعين على اختيار مدى بلوغنا لهذه 
الأهداف. وبكل ذلك يمكن تشخيص نواحي القوة والضعف، ومراجعة الخطط والطرق والأساليب، واتخاذ ما يلزم للعلاج والتحسين والتطوير. (سرحان، 1977: 95) قسم اللغة العربية وأدبها هو أحد قسم في كلية العلوم الإنسانية بجامعة مولانا مالك إبراهيم الإسلامية الحكومية مالانج. الرؤية من هذا القسم هي: يصبح أرقى الأقسام في القيام بالتعليم والتربية والدراسة وخدمة المجتمع حتى يتخرج منه الخريجون الخبراء في علم اللغة العربية وأدبها الذين يتميزون بالعقيدة الراسخة والروح العميقة والأخلاق السامية وآفاق المعرفة الواسعة والاحتراف الناضج، ومركزا لتطوير العلوم والتكنولوجيا والفن المتأسس على الإسلام، وقوة دافعة للمجتمع. والرسالة من هذا القسم هي: 1. تنفيذ التربية المتأسس علي القيم الإسلامية في إعداد الخريجين الخبراء في علم اللغة العربية وأدبها الذين يتميزون بالعقيدة الراسخة والروح العميقة والأخلاق السامية وآفاق

$$
\text { المعرفة الواسعة والاحتراف الناضج. }
$$

2. تنفيذ التربية والتعليم المتأهل في إعداد الخريجين الخبراء في علم اللغة العربية وأدبها،

$$
\text { والذين يتأهلون في تطبيقهما، علما كان أم عملا. }
$$

3. تنفيذ الدراسات والبحوث لتطوير علم اللغة العربية وأدبها واستيعابهما. 4. تنمية خدمة المجتمع المتأهلة لمعالجة المشكلة الدينية الاجتماعية، وتقديم خدمة

$$
\text { المجتمع في مجال علم اللغة العربية وأدبها. }
$$

5. المحافظة علي الأخلاق الأكاديمية لتطوير قسم اللغة العربية وأدبها. malang.ac.id/)

هذه المقالة البسيطة تبحث عن خصائص المواد الاختيارية في هذا القسم و الموافقة بين المنهج الدراسي لمواد الاختيارية وإجراء ممارسة التعليم الميدني (PKLI). واطلاع هذه المقالة لمعرفة تطبيق منهج الدراسي لمواد الاختيارية في قسم اللغة العربية وأدبها من قبل الطلبة. ويرجى بهذا التقويم ظهرت المواد التي تحقق ما بين النظري والتطبيق، وأن تكون جسر بينها وسوف يكون المنهج الدراسي يحقق بحياة الطلبة ويفيد في حياتهم.

$$
\text { ب. البحث) أعريف المنهج وأهميته }
$$


1. مجموعة من المقررات، أو المواد الدراسية التي تلزم للتخرج، أو الحصول على درجة

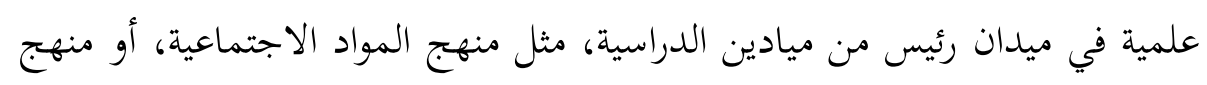
الرياضيات.

2. خطة عامة شاملة للمواد التي ينبغي أن يدرسها التلميذ بالمدرسة ليحصل على درجة

$$
\text { علمية (شهادة) تؤهله للعمل بمهنة أو حرفة. }
$$

3. مجموعة من المقررات والخبرات يكتسبها التلميذ تحت توجيه المدرسة أو الكلية.

$$
\text { (عميرة، 1991: 29). }
$$

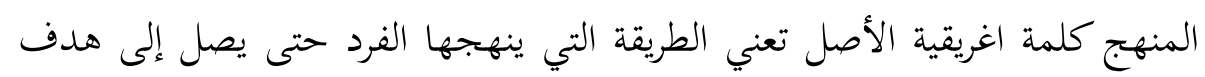

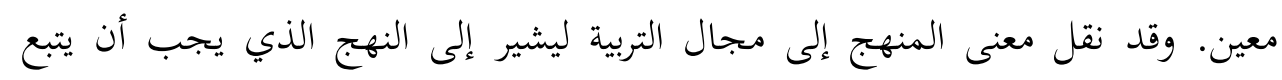

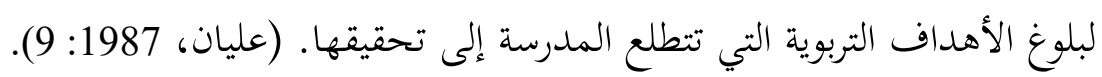

$$
\text { ب) عناصر المنهج }
$$

تتدرج الأهداف في حجمها وفي عمومها وفي شمولها وعلى هذه الأسس تهن

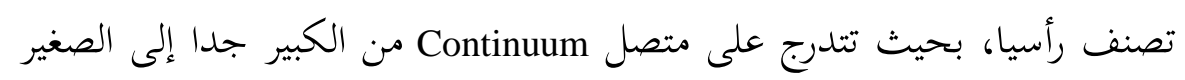

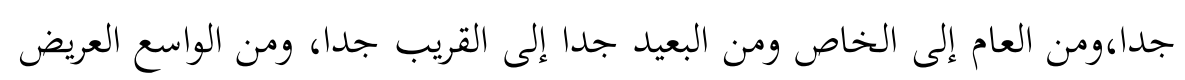
إلى الضيق.

فأعم الأهداف التربوية وأشملها وأعرضها وأبعدها هي ((غايات التربية

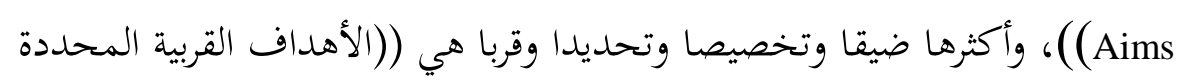

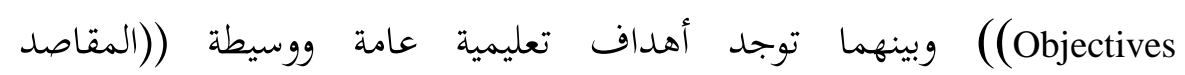

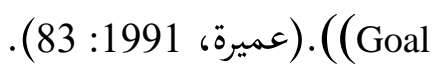

تصنيف الأهداف التربوية عديدة، كما رأي بلوم وزملائه للأهداف التربوية أحد

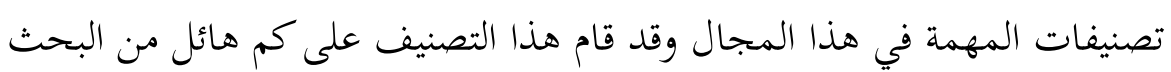

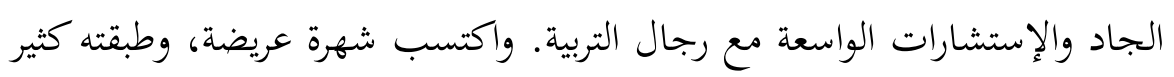

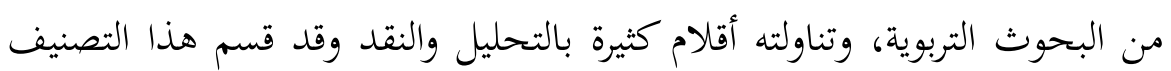

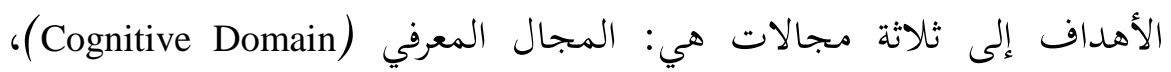
المجال الوجدانى (Affective Domain)، المجال النفسحركى (Psychomotor)

$$
\text { (عomain) }
$$




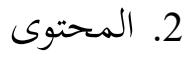

يتكون محتوى المنهج من حقائق ومبادئ وتعريفات وتفسيرات، أي من

معارف، كما يضم عمليات ومهارات كالقراءة، والحسابه، والملاحظة والتصنيف والقياس والاتصال والاستنتاج، والتفكير الناقد، واتخاذ القرارات، ويشتمل كذلك على قيم ومعتقدات عن الخير والشر، والصواب والخطأ، والجمال والقبح، والحياة الفاضلة والتنافس والتعاون. وجوانب المحتوى هذه توجد مترابطة متماسكة متلاحمة في المنهج وكل خبرة يمر بها المتعلم لها هذه الجوانب: المعارف، العمليات والمهارات، والقيم والمعتقدات، أو الجانب المعارفي، والجانب

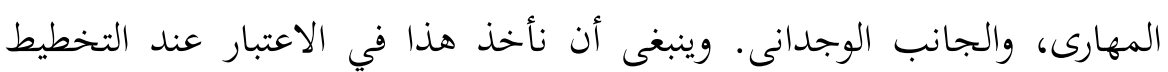

$$
\text { 3. نشاط التعليم والتعلمّم (عميرة، 1991: 129). }
$$

تحتل نشاطات التعليم والتعلم مكان القلب من المنهج، لأن لها تأثيرا كبيرا في تشكيل خبرات المتعلم، ومن ثم تغيير سلوكه، أو بعبارة أخرى ((تربية)) ونشاطات التعليم والتعلم وليس المحتوى بذاته، هي الوسيلة لتحقيق أهداف التعلم. والأهداف الجيدة والمحتوى الجيد لا تعنى الكثير إذا لم تتمخص نشاطات

$$
\text { التعليم والتعلم عن اكتساب التلاميذ للخبرات التربية المرغوبة. }
$$

ويمكن تعريف نشاط التعليم والتعلم، بأنه كل نشاط يقوم به المعلم أو المتعلم أو هما معا، أو يقوم به زائر أو متخصص لتحقيق الأهداف التربوية أو التعليمية والنمو الشامل المتكامل للمتعلم شواء تم داخل الفصل أو خارجه، داخل المدرسة أو خارجها، طالما أنه يتم تحت إشراف المدرسة. (عميرة، 1991: 231-232).

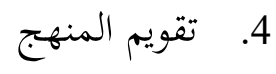

عند عميرة، التقويم هو العملية التي تستخدم فيها نتائج القياس، وأي معلومات يحصل عليها بوسائل أخرى مناسبة، في إصدار حكم على قيمة خاصة معينة لدى

$$
\text { المتعلم أو على جانب معين من جوانب المنهج. (عليان، 1987: 250). }
$$

إن كان التقويم أمرا حتميا في جميع مجالات الحياة. فإن أهميته تتزايد في

$$
\text { المجال التربوي لأسباب متعددة في مقدمتها ما يأتي: }
$$

1) تعيش التربية في الوقت الحاضر عصرها الذهبي. فهي فن بها البشر الذين يرتفع على كواهلهم صرح الحضارة، ويتم على أيديهم وبأفكارهم كل تقدم في 
مجالات العلم والاجتماع والاقتصاد وغيرها من المجالات. ولقد أصبحت

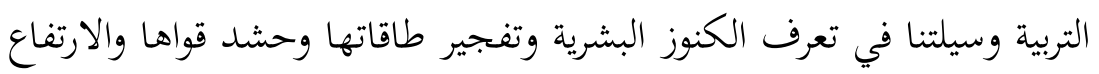

$$
\text { تمستواها. }
$$

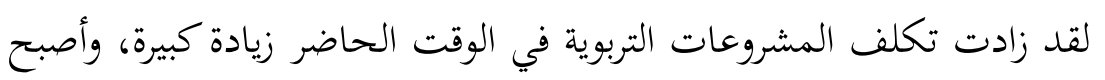

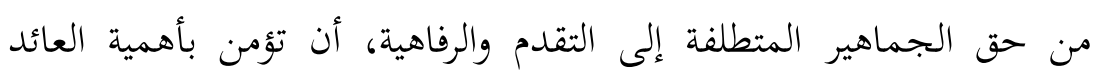

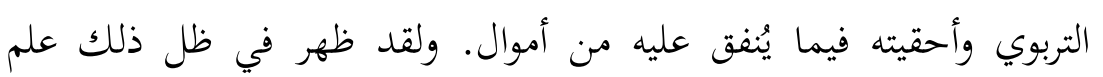
الإقتصاديات التعليم، الذي يستهدف ترشيد الأنفاق وتحسين العائد والنتائج.

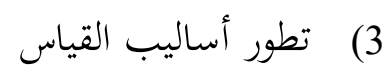

لقد تزايدت أهمية القياس والتقدير الكمي في عصر العلم والتكنولوجيا،

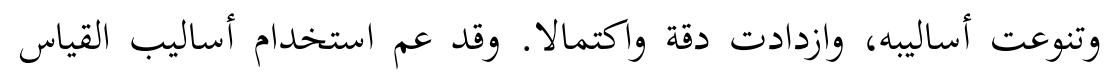
الجديدة في المجال التربوي وصولا بالعائد والناتج إلى أعلى المستويات. ملاحقة التقدم المعاصر في التربية

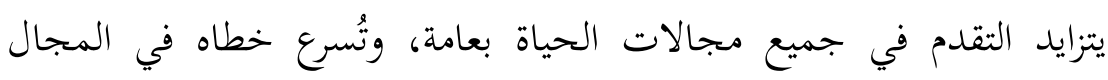

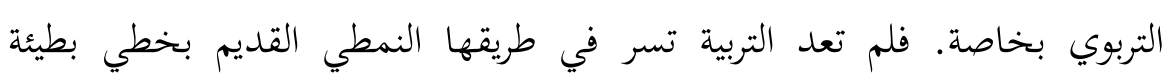

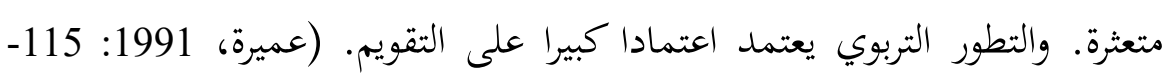

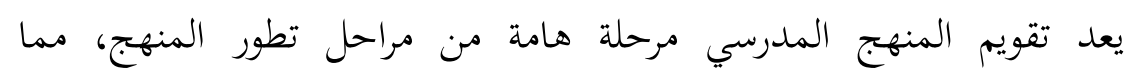

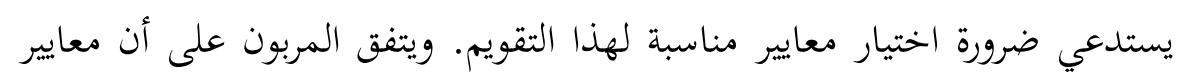

$$
\begin{aligned}
& \text { تقويم المنهج تتمثل فيما يلي: } \\
& \text { 1 ) ملاءمة المنهج المدرسي لحاجات المجتمع. }
\end{aligned}
$$$$
\text { 2) ملاءمة للحاجات السيكولوجية للمتعلمين. }
$$

3) ملاءمة للتطورات الحاصلة في المعارف والحقائق الإنسانية.

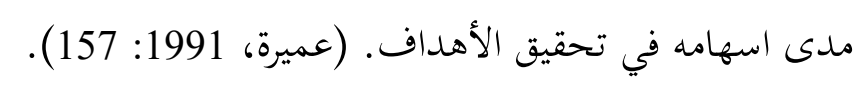

\section{ج) لمحة عن المنهج الدراسي في قسم اللغة العربية وأدبها}

قسم اللغة العربية وأدبها هو إحدي الأقسام في كلية العلوم الإنسانية التابعة لجامعة

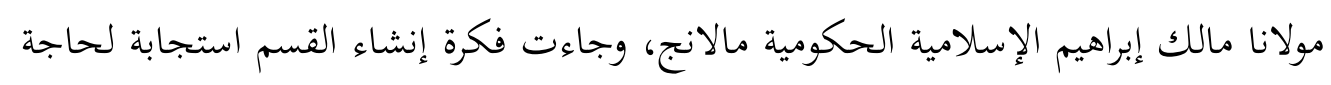


المسلمين الإندونيسيين إلي اللغة العربية كجزء من دينهم، وأنشأ قسم اللغة العربية وأدبها سنة 1998 بموجب المرسوم من جانب مدير شؤون المؤسسات الإسلامية لوزير الشؤون الدينية بجاكرتا رقم E/107/1998 وتاريخ 13 مايو 1998. ونال على الدرجة الممتازة من قبل هيئة

الجودة الوطنية بموجب المرسوم سنة 2008 وسنة 2013. (http://bsa.uin-malang.ac.id) كان المنهج المستخدمة في قسم اللغة العربية وأدبها هو المنهج الدراسي في السنة 2014. هذا المنهج تتكون على مواد التنمية الشخصية والمواد المعارفية والمهارة والمواد مهارات العمل (للتخصص الأدبي واللغوي) والمواد سلوك العمل والمواد في حياة المجتمع. والمنهج الدراسي في قسم اللغة العربية وأدبها هو عبارة عن دمج بين علوم اللغوية والعلوم الأدبية والإسلامية، وتستند تدوين هذا المنهج على التطورات والإحتياجات المجتمع. تنقسم قسم اللغة العربية وأدبها إلي تخصصين، التخصص الأدبي والتخصص اللغوي. ولتزويد الطلبة في ممارسة التدريب المهني (PKLI) أعد هذا القسم المواد الاختيارية التي تتكون على المواد التعليمية والترجمة والحج. كما وردت في جدول المناهج لقسم اللغة العربية وأدبها كما يلي:

(Matakuliah Pengembangan Kepribadian)

\begin{tabular}{|c|c|c|c|c|}
\hline الشرط & 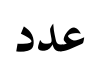 & المواد الدراسية & رمز المواد & رقم \\
\hline & 2 & التربية الوطنية & 1400101 & .1 \\
\hline & 3 & اللغة الإندونيسية & 1400102 & .2 \\
\hline & 3 & اللغة الإنجايزية 1 & 1400103 & .3 \\
\hline & 3 & اللغة الإنجايزية 2 & 1400104 & .4 \\
\hline & 1 & المدخل إلى علم الطبيعة & 1400106 & .5 \\
\hline & 2 & فلسفة & 1400107 & .6 \\
\hline & 2 & دراسة قرآنية والحديثة & 1400108 & .7 \\
\hline & 2 & دراسة الفقهية & 1400109 & .8 \\
\hline & 2 & دراسة الكلام والتصوف & 1400110 & .9 \\
\hline & 2 & تاريخ الحضارة الإسلامية & 1400111 & .10 \\
\hline & 1 & اللغة العربية (الاستماع 1) & 1400112 & .11 \\
\hline
\end{tabular}




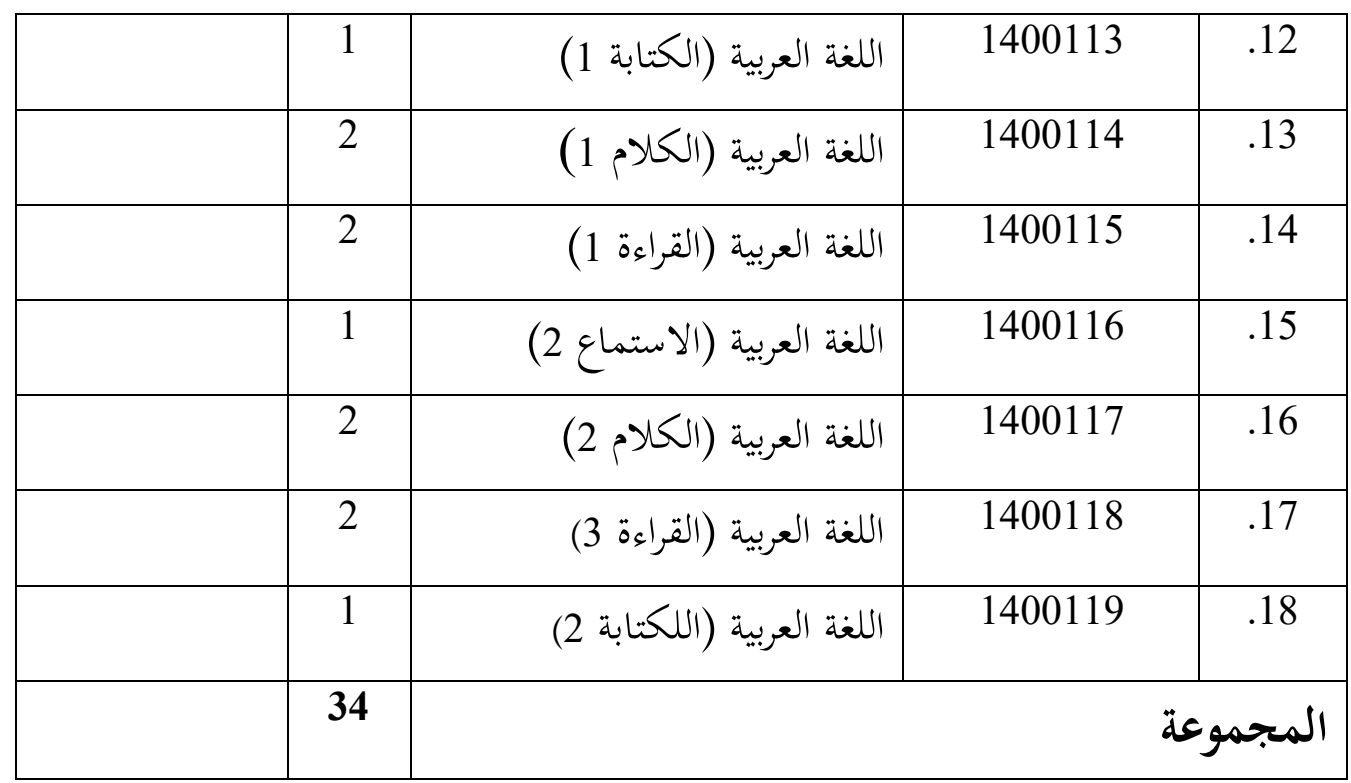

ب. بواد المعرفية والمهارة (Matakuliah Keilmuan dan Keterampilan)

\begin{tabular}{|c|c|c|c|c|}
\hline الشرط & عدد & المواد الدراسية & رمز المواد & رقم \\
\hline & 2 & مهارة القراءة 1 & 1431201 & .1 \\
\hline & 2 & مهارة القراءة 2 & 1431202 & .2 \\
\hline & 2 & مهارة الكتابة 1 & 1431203 & .3 \\
\hline & 2 & مهارة الكتابة 2 & 1431204 & .4 \\
\hline & 2 & مهارة الإستماع & 1431205 & .5 \\
\hline & 2 & فن الكلام & 1431206 & .6 \\
\hline & 2 & قواعد الإملاء & 1431207 & .7 \\
\hline & 2 & الخط العربي & 1431208 & .8 \\
\hline & 2 & علم النحو 1 & 1431209 & .9 \\
\hline & 2 & علم النحو 2 & 1431210 & .10 \\
\hline & 3 & علم النحو 3 & 1431211 & .11 \\
\hline & 2 & علم الصرف 1 & 1431212 & .12 \\
\hline & 2 & علم الصرف 2 & 1431213 & .13 \\
\hline
\end{tabular}




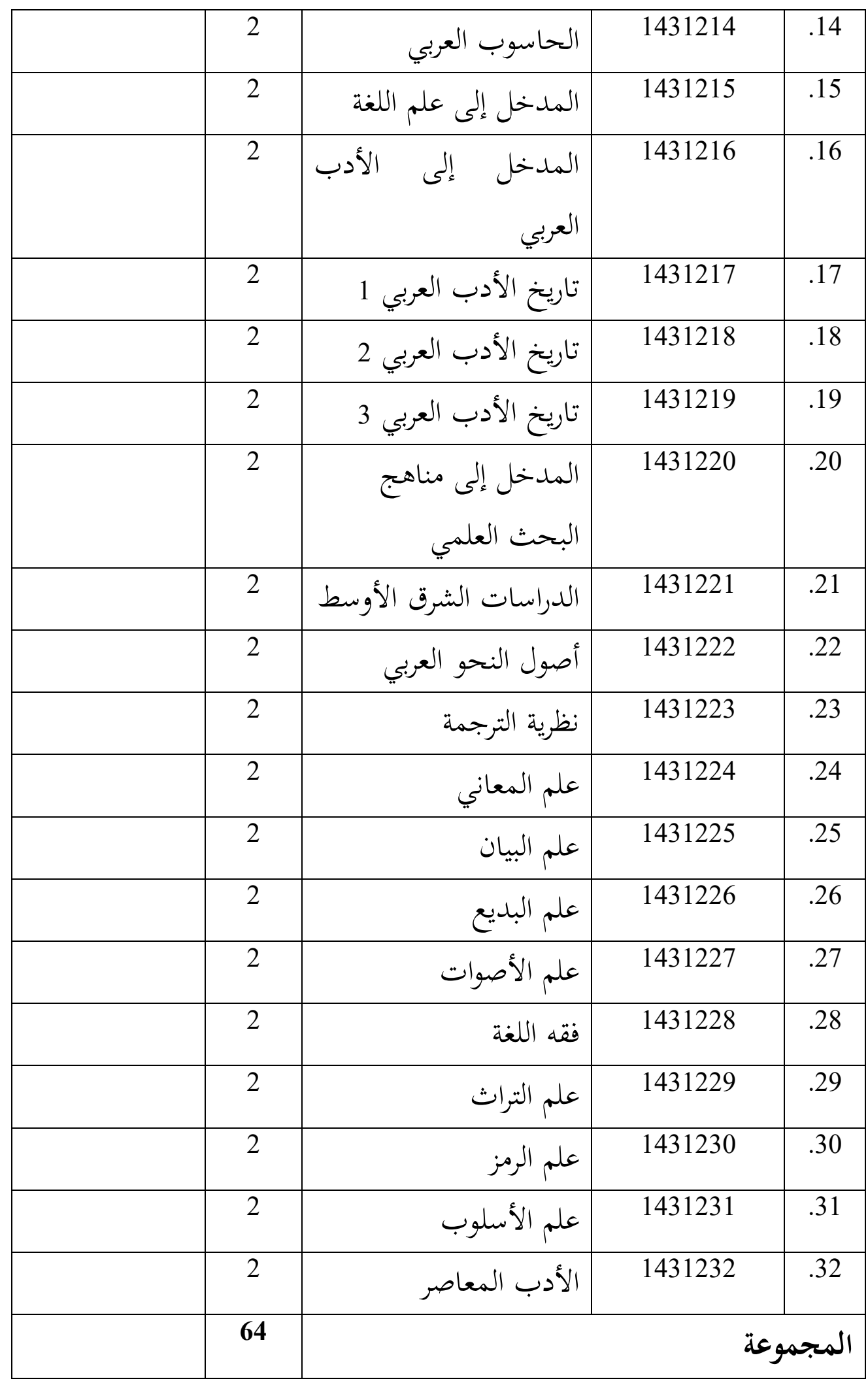

ج.مواد الاحترافية والعملية (Matakuliah Keahlian Berkarya) 


\begin{tabular}{|c|c|c|c|c|}
\hline الشرط & 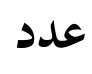 & المواد الدراسية & رمز المواد & 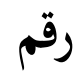 \\
\hline & 2 & نظرية الأدب & 1431301 & .1 \\
\hline & 2 & علم العروض والقوافي & 1431302 & .2 \\
\hline & 2 & نقد الأدب & 1431303 & .3 \\
\hline & 2 & الكتابة الإبداعية & 1431304 & .4 \\
\hline & 2 & 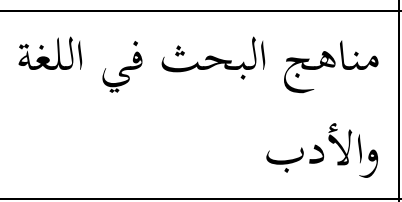 & 1431305 & .5 \\
\hline & 2 & علم الأدب الإجتماعي & 1431306 & .6 \\
\hline & 2 & فن المسرحية & 1431307 & .7 \\
\hline & 2 & | الأدب الشعبي & 1431308 & .8 \\
\hline & 2 & علم الدلالة & 1431309 & .9 \\
\hline & 2 & 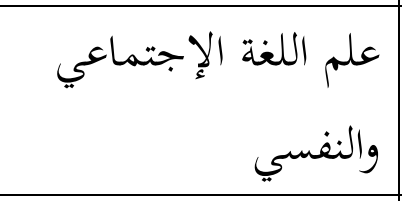 & 1431310 & .10 \\
\hline & 2 & علم اللهجات & 1431311 & .11 \\
\hline & 2 & علم التداولي & 1431312 & .12 \\
\hline & 2 & لسانيات الحديثة & 1431313 & .13 \\
\hline & 2 & علم المعاجم & 1431314 & .14 \\
\hline & 2 & | التحليل اللغوي & 1431315 & .15 \\
\hline & 30 & \multicolumn{3}{|c|}{ لمجموعة } \\
\hline
\end{tabular}

ج.1. المواد التعليمية

\begin{tabular}{|c|c|c|c|c|}
\hline الشرط & عدد & المواد الدراسية & رمز المواد & رقم \\
\hline & 2 & أسس التعليم وطرقته & 1431321 & .1 \\
\hline & 2 & تنمية المناهج & 1431322 & .2 \\
\hline
\end{tabular}




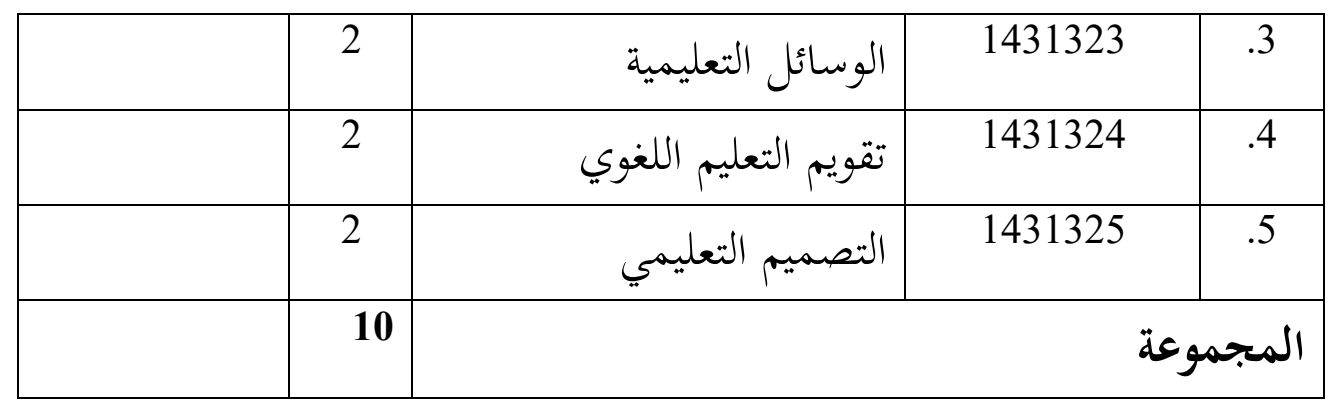

ج.2. المواد الترجمة والصحافة

\begin{tabular}{|c|c|c|c|c|}
\hline الشرط & عدد & المواد الدراسية & رمز المواد & رقم - ل \\
\hline & 4 & تطبيق الترجمة 1 & 1431331 & .1 \\
\hline & 2 & تطبيق الترجمة 2 & 1431332 & .2 \\
\hline & 2 & نقد الترجمة & 1431333 & .3 \\
\hline & 2 & الصحافة العربية & 1431334 & .4 \\
\hline & 10 & \multicolumn{3}{|c|}{ لمجموعة } \\
\hline
\end{tabular}

ج.3. مواد العربية للحج والعمل

\begin{tabular}{|c|c|c|c|c|}
\hline الشرط & عدد & المواد الدراسية & رمز المواد & رقم \\
\hline & 2 & المدخل إلى الصياحة & 1431341 & .1 \\
\hline & 2 & العربية للصياحة & 1431342 & .2 \\
\hline & 2 & إدارة الصياحة & 1431343 & .3 \\
\hline & 2 & العربية المعاصرة & 1431344 & .4 \\
\hline & 2 & العربية للحج والعمرة & 07314014 & .5 \\
\hline & 10 & & & \\
\hline
\end{tabular}

ج.4. المواد السينمائية

\begin{tabular}{|c|c|c|c|c|}
\hline الشرط & عدد & المواد الدراسية & رمز المواد & رقم \\
\hline
\end{tabular}




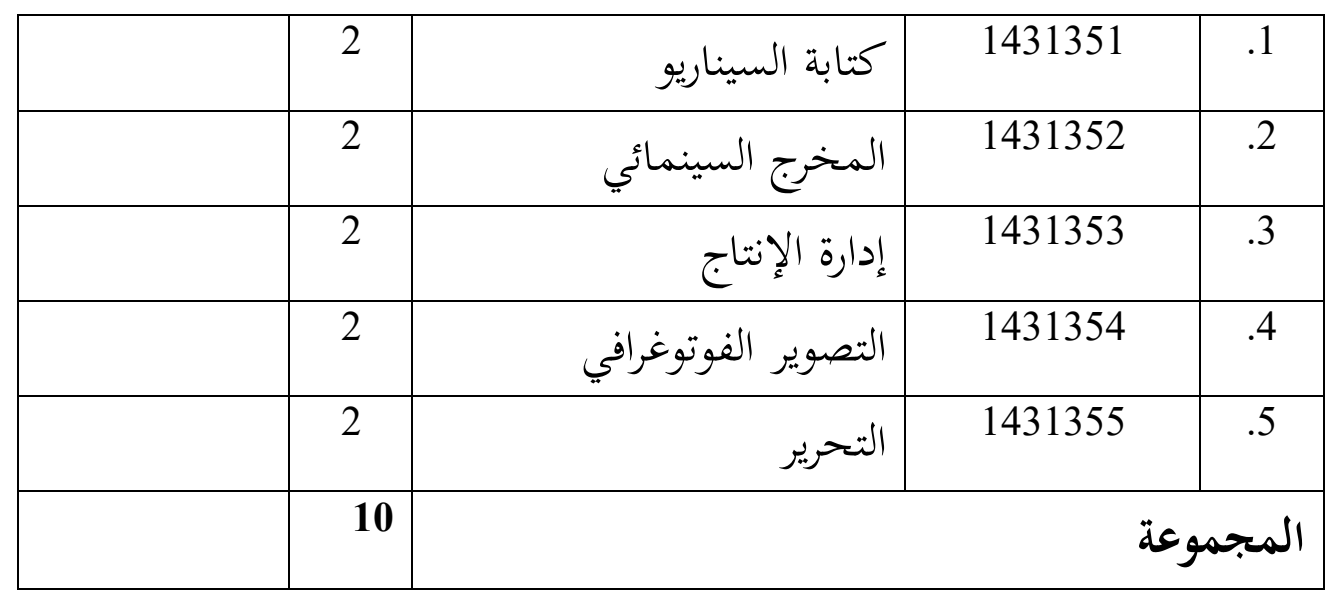

\section{د. مواد الحياة الإجتماعية (Matakuliah Berkehidupan Bermasyarakat)}

\begin{tabular}{|c|c|c|c|c|}
\hline الثرط & 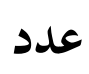 & المواد الدراسية & رمز المواد & 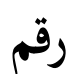 \\
\hline & 2 & المجتمع والثقافة الإندنيسية & 143101 & .1 \\
\hline & 2 & ممارسة التعليم الميداني & 143102 & .2 \\
\hline & 2 & ممارسة التدريب المهني & 143103 & .3 \\
\hline & 6 & \multicolumn{3}{|c|}{ المجموعة } \\
\hline
\end{tabular}

هـ. مواد السلوكية والعملية (Matakuliah Prilaku Berkarya))

\begin{tabular}{|c|c|c|c|c|}
\hline الشرط & عدد & المواد الدراسية & رمز المواد & رقم \\
\hline & 6 & البحث العلمى & 1431501 & .1 \\
\hline & 6 & & \multicolumn{2}{|c|}{ المجموعة } \\
\hline
\end{tabular}

\section{ج. منهج البحث \\ 1. 1 نوع البحث وتصميم البحث}

استخدمت الباحثة في هذه الدراسات منهج الوصفي الكيفي. والمدخل هذا

البحث هو البحث التقويمي كما قال بوغين، أن أنواع الدراسات من ناحية الغرض هي

الدراسات التقويمية. وفي الغالب هذه الدراسة لإجابة السؤال: ما مدى حقق المشروع 
وفقا لأوجز. (Bungin, 2001 (30) وعند نانا شؤوديه سكماديناتا، بأن البحث التقويمي هو تصميم وإجراء التقويم لجمع وتحليل البيانات بشكل منهجي لتعيين نتيجة القياس أو جمع البيانات باستخدام المعيار المعين الذي يستخدم في مطلق أو لورئر نسبي. (Sukmadinata, 2011: 120)

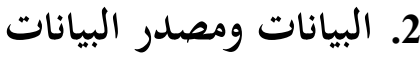

والبيانات من هذا البحث هي القرارات يعنى أخذت الباحثة البيانات من المنهج الدراسي وآراء المعلمين في المواد الاختيارية والطلبة الذين يدرس هذه المواد. ومصدر البيانات هي عملية التعليمية أي الأنشطة التعليمية في هذه المواد الاختيارية الثلاثة (العربية للتعليم والترجمة والصحافة والعربية للحج).

\section{3 - أدوات جمع البيانات}

اختلفت أدوات جمع البيانات في المنهج الكمي والكيفي. كان المنهج

الكمي يستعمل الإختبار، والمنهج الكيفي يستعمل جمع البيانات الطبيعية وعند ظروف (Setiyadi, . فورية. ولكن عند إجراء البحث أحيانا جمعت الباحثة بين تلك الأدوات (2006: 151. وأدوات المستخدمة لجمع البيانات في هذا البحث هي:

أولا: الملاحظة.

لملاحظة أوسع وسائل جمع المادة انتشارا. فهي تستخدم في كافة أنواع البحوث بإستثناء البحوث التاريخية أما الفلاسفة فإنهم يقيمون التأمل مقام الملاحظة. وقامت الباحثة الملاحظة عن بعد (بدون المشاركة) فإن الباحث يقف بعيدا ولا يشارك في أنشطة المجموعة التي يقوم بملاحظتها والمهم أن لا يذكرهم بوجوده دائما ولا يفصح له عن أهدافه الأساسية إلا في مراحل الملاحظة المتأخرة.(عثمان، 1995: 131132). قامت الباحثة بملاحظة لمعرفة العملية التعلمية وإجراء ممارسة تعليم الميداني في قسم اللغة العربية وأدبها. ثانيا: المقابلة. وتعتبر المقابلة الشخصية واحدة من الطرق المسحية في البحوث الاجتماعية تستخدم لتجميع البيانات أو الاختبار الفروض البحثة وتعرف المقابلة بأنها محادثة بين شخصين يبدأها الشخص الذي يجري المحادثة وتتم الأهداف معينة منها الحصول على معلومات وثيقة الصلة بالبحث ويركز فيها على محتوى محدد بأهداف 
بحثية. (عثمان، 1995: 134). وجرت المقابلة لهذا البحث يعني المقابلة حول إجراء تعليم المواد الاختيارية وكذلك لمعرفة موافقة المنهج الدراسي بممارسة التدريب المهني (PKLI) الاختيارية. وجرت هذه المقابلة لمعلم المواد الاختيارية والطلبة في المرحلة الثامنة الذين اشتركوا في ممارسة التدريب المهني (PKLI) بقسم اللغة العربية وأدبها. ثالثا، الوثائق. الوثائق هي إحدى مصدر البيانات في المنهج الكيفي. هذا المصدر البيانات لها بعض الزائدة مقارنة بمصادر الأخرى. هذا المصدر كمصدر الطبيعية ويمكن الحصول عليها بسهولة. (Setiyadi, 2006:249) استخدمت الباحثة هذه الطريقة لجمع البيانات التي تتعلق بالمنهج الدراسي والكتب والدوريات المتعلقة بهذا البحث.

\section{4. - n ت تحليل البيانات}

تستخدم الباحثة تحليل السرد الكيفي (Analysis Naratif Kualitatif). ( وهذا التحليل يكون وصف السرد الكيفي عن الأمور (Sukmadinata, 2011: 136) .

$$
\begin{aligned}
& \text { المهمة في هذا البحث التقويمي. } \\
& \text { والخطوات لتحليل البيانات الكيفي كما قال موليونج بخطوط التالية: } \\
& \text { 1. تدوين نتيجة الملاحظات في الميدانية وترميز مصدر البيانات. } \\
& \text { 2. جمع واختيار وتصنيف وتلخيص البيانات. } \\
& \text { 3. الفكر بجعل فئات البيانات التي تجعل من عملية البحث على أنماط ذات معنى وتصنيف } \\
& \text { وعلاقات العامة وجعل النتائج العامة.(Moleong, 2005: 248) }
\end{aligned}
$$

\section{د. النتيجة والمناقشة}

إن خصائص المواد الاختيارية متعلقة بحاحات الطلبة بعد تشخيص وتحليل أنواع الحاحات المحتاجة لمواجهة مستقبل الطلبة. إذن أنواع المجالات المطروحة لدى الطلبة في

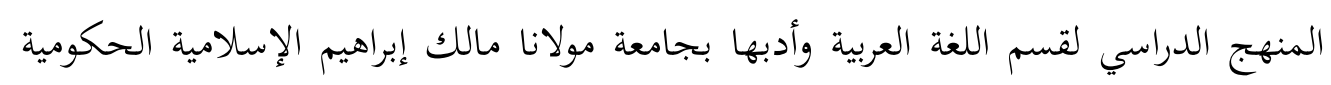
مالانج هي: مجال التعليم والترجمة والصحافة والعربية للحج والعمل والسينمائية. واختار الطلبة هذه المواد حسب ميولهم. 
وأما الكفاءة الأساسية المرجوّة من المتخرّجين بقسم اللغة العربية وأدبها هي العقيدة الراسخة وتعميق الروحية، والأخلاق السامية، وآفاق المعرفة الواسعة والإحتراف الناضج. والكفاءة الجانبية هي أن يكون معلم اللغة العربية في المدارس، والمترجم، ومشرف مناسك الحج في مجال اللغة العربية ومفتّش في مجال اللغة العربية ومستشار اللغة العربية في مركز اللغة ومشرف في مجال السياحة والحج والعمرة.

نتيجة المقابلة من بعض الطلبة في مجال التعليم بأن وجود الموافقة بين المنهج الدراسي لمواد الاختيارية وإجراء ممارسة تعليم الميداني وهي في مواد تنمية المناهج، والوسائل التعليمة، وتصميم التعليميي، وتقويم الدراسي، ولها إسهامات الهامة أثناء إجراء ممارسة التدريب المهني (PKLI) وحينما قام الطلبة بالدراسة في المدارس، هذه المواد الاختيارية تساعدهم في إعداد عملية التدريس وصناعة أدوات التدريس.وجميع المواد الاختيارية لها فائدة كثيرة ولكن بسبب قلة التركيز يجعل عدم الفهم التامة والكاملة من قبل الطلبة. 1 وفي مجال الترجمة كانت المواد الاختيارية لها مطابقة قوية ومتينة حول النظرية وتطبيق لهما علاقة قوية كتطبيق مادة الترجمة 1و2 ومادة نقد الترجمة. واستطاع الطلبة لتطبيق المواد حسب ما حصل في الفصل ويساعدهم عند إجراء LQiS, Ar- ممارسة التدريب المهني (PKLI) في مكان طباعة الكتب بجكجاكرتا مثل 2 . El-SaQ Ruzz وأما في مجال الحج، أغلبية المواد الاختيارية لها موافقة بممارسة التدريب المهني (PKLI) طرق التدريس العربية ومناسكه عند إحدى الطالبات غير مهمة، بسبب مضمون الدرس متساويان بتاريخ الحج ومناسكه، إذن أصبح اختلاطا وأحسن أن تغيّر بالمادة الأخرى التي لها إسهام هام كمثل المادة عن إدارية الحج في مجموعة إرشاد الحج (KBIH). لأن هذه المادة تحتاجها الطلبة عند ممارسة التدريب المهني (PKLI). 3 
ونتيجة المقابلة من المدرسين، بأن إيجاد المواد الاختيارية مناسبة بحاجات الطلبة نظرا من الكفاءة والمهارة التي يجب أن تكون ممتلكة والتحكم عليهم لمواجهة مستقبلهم. 4 وإيجاد موافقة بين المنهج الدراسي والمواد الاختيارية بقسم اللغة العربية وأدبها والمواد المطروحة في مجال الحج جيدة وربما ليس هناك زيادة المادة الأخرى لأن هذه المواد المحتاجه لدى الطلبة ولديها إسهام قوي في تطبيق من خلال المجتمع. 5 ويري المعلم في مجال الترجمة، أن مجموعة المواد الاختيارية المطروحة بقسم اللغة العربية وأدبها كافية جعل الطلبة لهم الكفاءة الجيدة في فن الترجمة ويؤدي إلى ظهور أنواع من أعمال الترجمة من قبل الطلبة لكل السنة. ومن الموضوعات التي ترجم من اللغة العربية إلى اللغة الإندونيسية هي بعض موضوعات من الروايات لنجيب محفوظ، ولنجيب كيلاني، وطه حسين، وأشبه ذلك. 6

نظرا من البيان السابق، أن معظم المنهج الدراسي لمواد الاختيارية بقسم اللغة العربية وأدبها بكلية الإنسانية بجامعة مولانا مالك إبراهيم الإسلامية الحكومية بمالانج لها موافقة بممارسة التدريب المهني (PKLI)، ولكن وجدت المادة غير موافقة من جهة مضمون المادة وقلة التركيز في بعض المواد تؤدي إلى عدم الفهم الكامل من قبل الطلبة.$$
\text { المراجع }
$$$$
\text { المراجع العربية }
$$$$
\text { إبراهيم بسيوني عميرة. 1991. المنهج وعناصره. القاهرة: دار المعارف. }
$$$$
\text { الدمرداش عبد المجيد سرحان. 1977. المناهج المعاصرة. الكويت. }
$$$$
\text { رشدي أحمد طعيمة. 1989. تعليم العببية لغير الناطقين بها مناهجه وأساليبه. الرباط: منشورات }
$$$$
\text { المنظمة الإسلامية للتربية والعلوم والثقافة-إيسييسكو. }
$$

4 4 مقابلة بأحد المعلم في مجال التعليم. في التاريخ 25 أكتوبر 2017.

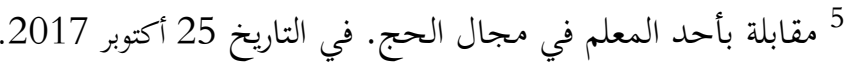

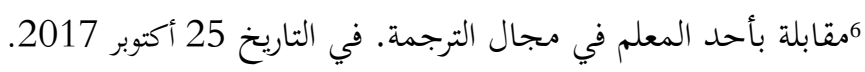




$$
\text { تقويم المنهج الدراسي لمواد الاختيارية في قسم اللغة العربية... }
$$

$$
\text { مجاء وحيد دويدري. }
$$$$
\text { كلية العلوم الإنسانية والثقافة جامعة مولانا مالك إبراهيم الإسلامية الحكومية مالانج. 12-14 }
$$$$
\text { اكتوبر } 2010 .
$$

مجموعة البحوث الندوة الدولية حول تجربة تعليم اللغة العربية في إندونسيسا ما لها وما عليها.

بمناسبة اليوم العالمي للغة العربية. مالانج: البرنامج الخاص لتعليم اللغة العربية جامعة مولانا ما

$$
\text { لك إبراهيم الإسلامية الحكومية بمالانج. }
$$

\section{المراجع الأجنبية.}

Bungin, Burhan. 2001. Metodologi Penelitian Sosial. Surabaya: Airlangga University Press.

Moleong, Lexy J.. 2005. Metodologi Penelitian Kualitatif. Bandung: Rosdakarya. Muhaimin. 2007. Pengembangan Kurikulum Pendidikan Agama Islam di Sekolah,

Grafindo Persada. Madrasah, dan Perguruan Tinggi. Jakarta: PT. Raja

Pendoman Pendidikan Fakultas Humaniora dan Budaya Universitas Islam Negeri Maulana Malik Malang Tahun 2011.

Sukmadinata, Nana Syaodih. 2011. Metode Penelitian Pendidikan. Bandung: PT. Rosdakarya. Remaja

Setiyadi, Ag. Bambang. 2006. Metode Penelitian Untuk Pengajaran Bahasa Asing Pendekatan Kualitatif dan Kuantitatif. Yogyakarta: Graha Ilmu.

\section{Internet}

diakses pada 16 Nopember 2017http://bsa.uin-malang.ac.id/ 